\title{
Why do we Need Randomized and Epidemiological Studies on Cardiovascular Disease? Evidence-based Cardiology VII
}

\author{
Álvaro Avezum, João Manoel Rossi Neto, Leopoldo Piegas
}

São Paulo, SP - Brazil

\begin{abstract}
Over the last two decades the results of randomized clinical studies, which are powerful aids for correctly assessing therapeutical strategies, have consolidated cardiological practice. In addition, scientifically interesting hypotheses have been generated through the results of epidemiological studies. Properly conducted randomized studies without systematic errors and with statistical power adequate for demonstrating moderate and reasonable benefits in relevant clinical outcomes have provided reliable and strong results altering clinical practice, thus providing adequate treatment for patients with cardiovascular disease (CVD). The dissemination and use of evidence-based medicine in treating coronary artery disease (CAD), heart failure (HF), and in prevention will prevent hundreds of thousands of deaths annually in developed and developing countries.

CVD is responsible for approximately 12 million deaths annually throughout the world, and approximately $60 \%$ of these deaths occur in developing countries. During recent years, an increase in mortality and morbidity rates due to CVD has occurred in developing countries. This increase is an indication that an epidemiological (demographic, economical, and health-related) transition is taking place in developing countries and this transition implies a global epidemic of CVD, which will require wide-ranging and globally effective strategies for prevention. The identification of conventional and emerging risk factors for CVD, as well as their management in high-risk individuals, has contributed to the decrease in the mortality rate due to CVD.

Through a national collaboration, several multi-center and multinational randomized and epidemiological studies have been carried out throughout Brazil, thus contributing not only to a generalized scientific growth in different Brazilian hospitals but also to the consolidation of an increasingly evidence-based clinical practice.
\end{abstract}

Instituto Dante Pazzanese de Cardiologia - São Paulo

Mailing address: Álvaro Avezum - Instituto Dante Pazzanese de Cardiologia - Av. Dr. Dante Pazzanese, 500 - 04012-180 - São Paulo, SP

\section{Introduction}

Randomized clinical studies have provided therapeutic strategies over the past two decades that have led to the consolidation of cardiology practice. Without these studies, it is not possible to reliably prove the effects of a determined treatment on a clinical condition.

In addition, without scientifically interesting and promising hypotheses developed from the findings of epidemiological studies there would be no rationale for randomized studies.

Randomized studies confirm hypotheses raised by epidemiological studies. During the next decade, we may need more epidemiological studies to raise questions to be reliably answered in further randomized studies.

We will briefly discuss the need for randomized and epidemiological studies as additional techniques of scientific investigation to determine changes in the clinical practice that will optimize treatment of patients with CVD.

\section{Randomized studies}

Rationale for randomized studies - The criteria for an adequate clinical study are similar for most of CVDs: 1 ) to state an important clinical question; and 2) to answer this question in a reliable manner. The answers to these questions may suggest a range of large simple randomized studies of the effects of several treatments on mortality applied to common cardiovascular conditions. These studies comprise six steps: 1 ) the identification of effective treatments is probably more important if the disease to be studied is a common and not a rare one; in addition, studies on common diseases can be large; 2) the identification of effective treatments for common diseases is probably more important if the treatment is widely applicable instead of complex; in addition, protocols for widely applicable treatment can be simple; 3 ) studies of the effects of treatment upon significant clinical outcomes (i. e., death) are probably more important than those upon less significant outcomes (i. e., radiological or biochemical evidence of recurrence or progression of the disease); in addition, the follow-up protocol of significant clinical outcomes may frequently be simple; 4) the liability of the comparison between the treatments is increased little by the adjust- 
ments of any imbalances in prognostic characteristics, suggesting that the eligibility criteria can be simple; 5) the direction, but not necessarily the magnitude, of the benefit network of the treatment upon mortality is probably similar in different categories of randomized patients; and 6) most of the therapeutical interventions in cardiology produce moderate reductions in mortality, that is, the true reduction of the risk is probably between $10 \%$ and $25 \%$, instead of between $40 \%$ and $60 \%{ }^{1}$.

Considering that most of the treatments cause moderate, although reasonable, reductions in mortality, and knowing that this is confirmed by the observation of the results of the clinical studies available, we ask this question: How important would this effect be if it could be reliably predicted? Assuming that mortality in acute myocardial infarction (AMI) is a common event, reductions in mortality from $10 \%$ to $8 \%$ might be clinically significant and useful, preventing thousands of deaths annually throughout the world. In terms of absolute gains, hypothetically, the cure of less common diseases would have a smaller impact on public health than a reduction of $20 \%$ in mortality due to AMI.

Reduction in study bias - A great part of the information published about treatments, frequency of clinical events, and patterns of clinical practice come from observational records. Observational methods of data collection, such as description, are usually useful. They cannot, however, reliably compare the effects of different treatments because of the biases that emerge as a consequence of the inability to control for innumerable confounding factors. One of the most efficient and useful methods for reducing bias is the use of randomized controlled study ${ }^{1,2}$. True randomization can only occur in a blinded situation. In addition, study bias can be minimized if the treatment being assessed be blinded.

Moderate and plausible reductions - One important step in the development of the concept of large simple clinical studies was the acceptance of the hypothesis that proportionally moderate reductions in the relative risk (15\%$25 \%$ ) of relevant clinical outcomes (death, myocardial infarction, re-hospitalization due to $\mathrm{HF}$ ) will significantly impact the clinical practice ${ }^{2}$. These moderate reductions can be clinically valuable if they impact clinical conditions associated with significant morbidity and mortality, such as AMI, unstable angina, HF, etc. Furthermore, if the assessed treatments are of easy use, widely applicable, and of relatively low cost, the impact of this moderate benefit can be substantial (Table I). The reliable detection of moderate differences requires studies with sample size large enough to have adequate statistical power. Table II shows the estimates of sample sizes for studies, which are adequately powerful to detect risk reductions of $10 \%, 20 \%$ and $33 \%$. This way, the two most problematic biases in clinical assessment can be adequately handled in clinical studies: biases caused by subjective interpretation of data can be reduced through randomization, and the random errors caused by natural biological variability of responses can be reduced in studies large enough to show moderate differences ${ }^{3}$.

Requirements for reliable assessment of moderate effects of treatments - The reliability of a scientific investigation, with regard to different therapeutical strategies can be assured through the observation of the following: Objective - minimize systematic errors (biases). Strategyinclude adequate randomization, analysis of the intention of treatment (analysis through designated treatment), emphasis on global results (avoid the analysis of subgroups without a previously specified hypothesis), systematic revisions $^{3}$.

Essential characteristics of an adequate clinical study - Basically, a clinical study should address a relevant clinical question, which should, invariably, be correctly answered. The following characteristics, cited by R. Peto in $1978^{2}$, when properly applied lead to a clinical study of high quality and, consequently, to valuable and reliable results: a) large; b) randomized; c) correctly finished; d) reported without any exclusions; e) thoroughly and correctly analyzed; f) carefully interpreted.

Why mortality is an important clinical outcome? - It has been frequently reported in the cardiological literature about experimental or clinical studies that several promising and not yet proved treatments favorably modify important mechanisms involved in the cardiovascular disease process. For example, several therapeutical agents have reduced the size of infarction, the frequency of arrhythmias, have enhanced ventricular function and reduced the progression of atherosclerosis. However, these indirect

\begin{tabular}{|c|c|c|c|}
\hline \multicolumn{4}{|c|}{$\begin{array}{c}\text { Table I - Potential benefit in public health through the use of large } \\
\text { simple randomized studies demonstrating } 10 \%, 20 \% \text { and } 33 \% \\
\text { reductions of the risks }\end{array}$} \\
\hline $\begin{array}{l}\text { Absolute effect } \\
\text { of treatment }\end{array}$ & $\begin{array}{c}\text { Risk reduction } \\
(\%)\end{array}$ & $\begin{array}{c}\text { Lives saved } \\
\text { annually* }\end{array}$ & Comment \\
\hline From $15 \%$ to $13.5 \%$ & 10 & 15.000 & Realistic \\
\hline From $15 \%$ to $12 \%$ & 20 & 30.000 & Plausible \\
\hline From $15 \%$ to $10 \%$ & 33 & 50.000 & Unlikely \\
\hline \multicolumn{4}{|c|}{$\begin{array}{l}\text { *Assuming that } 1 \text { million people with an annual mean mortality rate of } \\
15 \% \text { could be treated (similar frequencies are observed for myocardial in } \\
\text { the USA). }\end{array}$} \\
\hline
\end{tabular}

\begin{tabular}{|cccc|}
\hline \multicolumn{3}{|c|}{ Table II - Estimated sample size for large simple randomized studies } \\
\hline \multirow{2}{*}{$\begin{array}{c}\text { Anticipated risk } \\
\text { reduction }(\%)\end{array}$} & \multicolumn{3}{c|}{ Frequency of expected events } \\
\cline { 2 - 4 } & $10 \%$ & $15 \%$ & $20 \%$ \\
\hline 10 & 36.000 & 22.700 & 16.000 \\
20 & 8.600 & 5.300 & 3.900 \\
30 & 3.600 & 2.300 & 1.650 \\
\hline \multirow{2}{*}{ Assuming two tailed alpha $=0.05,90 \%$ of power (1-beta) and two arms. } \\
\hline
\end{tabular}


markers of efficacy do not necessarily provide reliable and definite evidence of benefit to physicians to assess the efficacy of the involved agents. When a therapy reduces mortality, its benefits outweigh its risks and thus it can be considered as a safe option in clinical decision-making. It is often appropriate to evaluate the benefit of an intervention through the analysis of combined clinical outcomes as the primary objective of a study, as long as they are directly related to the prognosis in a particular clinical situation, for example, the evaluation of mortality combined with reinfarction in studies on AMI, mortality combined with infarction in studies on unstable angina, mortality combined with hospitalization due to congestive HF in studies of HF.

The impact of randomized studies upon clinical practice - Hundreds of thousands of premature deaths could be prevented through use of findings from controlled randomized studies on several effective and widely applicable treatments for conditions such as acute coronary syndromes, HF, prevention of CVD, as well as through the appropriate spread of the findings. It is estimated that the widespread use of the acetylsalicylic acid in CVD would prevent 100,000 deaths annually in developed countries and that this number might be greater in developing countries ${ }^{3}$. Efforts in prevention and treatment have been facilitated by demonstrations of the efficacy of such interventions as smoking cessation, reduction in lipids and blood pressure, as primary and secondary preventive measures; rapid and effective treatment of AMI with thrombolytic therapy, acetylsalicylic acid, and intravenous beta-blocker, longterm prophylaxis with beta-blockers, acetylsalicylic acid and angiotensin-converting enzyme inhibitors (ACEI); prolongation of the survival of patients with extensive coronary artery disease through myocardial revascularization; and prolongation of survival in patients with $\mathrm{HF}$ with the use of ACEI, beta-blockers and spironolactone. The demonstration of efficacy of these interventions requires large collaborative randomized studies. It is equally important to demonstrate the lack of efficacy or even the risk of many promising interventions, through wellconducted randomized studies. In conclusion, randomized clinical studies can be considered the gold standard for the assessment of the efficacy of most therapeutical interventions in CVD.

During the last two decades, the treatment of AMI has been well established through the results of controlled randomized studies. The use of treatments, such as fibrinolytic therapy, beta-blockers, acetylsalicylic acid and ACEI is based on large studies with adequate statistical power to demonstrate moderate, but reasonable, reductions in mortality (table III).

In addition, therapeutical management of symptomatic and asymptomatic ventricular dysfunction has been altered based on the results of randomized studies involving treatments with ACEI (SOLVD-Treatment, SOLVD-Preven-tion, SAVE, AIRE, TRACE studies), digitalis (DIG study), beta-blockers (US Carvedilol, CIBIS-
2, MERIT studies), and spironolactone (RALES study). These alterations have resulted in clinically important reductions in the relevant clinical outcomes, such as death and hospitalization due to HF.

Preventive strategies assessed in randomized studies with statins in primary and secondary prevention have been firmly defined through the demonstration of clinical benefits in relevant clinical outcomes, such as reduction of mortality and of the incidence of AMI in studies evaluating CVD (4S, CARE, LIPID, AFCAPS/TexCAPS studies). Therefore, in regard to clinical therapeutics in cardiology, it is only through the results of controlled randomized studies with adequate statistical power that we can alter clinical practice. The reliable and relevant clinical benefit can only arise from well-planned and well-conducted studies. Once again, we emphasize that it is important to always bear in mind the principle "too good to be true" as part of our analyses and interpretations about exaggerated reductions in relevant clinical outcomes (i. e., death, infarction, among others). The rule is to accept the direction of the effect of the treatment (decrease or increase), but to question or even be suspicious of great and loudly acclaimed benefits, such as a 60\%-decrease in mortality.

In addition, when testing two treatments, one of acknowledged efficacy and a new treatment with promising efficacy, we should expect small reductions of around $10 \%$ to $15 \%$ in relevant clinical outcomes (relative 14\%-reduction in mortality with the use of accelerated t-PA compared with streptokinase in the GUSTO study ${ }^{4}$ ). Therefore, we should be conservative when analyzing a comparison between two effective treatments.

\section{Epidemiological studies}

Rationale for the use of epidemiological studies-CVD is responsible for approximately 12 million deaths annually, being the most common cause of death. Around $60 \%$ of the deaths due to CVD (approximately 10.6 million deaths in 1990 ) occur in developing countries. ${ }^{5}$. CVD is the main contributor to precocious morbidity and mortality, accounting for 85 million disability-adjusted life years (DALYs-sum of the life years lost due to premature mortality and the years lived with a disabling condition adjusted to severity ${ }^{6}$ ). Projections to the year 2020 indicate that CVD will remain the main cause of mortality and disability and that the DALYs attributed to CVD will increase to 140-160 million, with the greatest increase occurring in developing countries $^{7}$. This expected increase in CVD reflects the demographic, economical and health-related transition in developing countries. Knowing this, a global epidemic of CVD is anticipated with a substantially greater impact upon the economically less-favored classes ${ }^{8}$. Therefore, really effective prevention needs a large and global social strategy, which requires the understanding of the emerging and already known risk factors for CVD, in distinct ethnical groups and geographical regions, including Brazil. 


\begin{tabular}{|c|c|c|c|c|c|c|}
\hline \multicolumn{7}{|c|}{ Tabela III - Summary of large simple studies in the acute myocardial infarction ${ }^{5}$} \\
\hline \multirow[t]{2}{*}{ Treatment } & \multirow[t]{2}{*}{ Agent } & \multirow[t]{2}{*}{ Main Result } & \multicolumn{2}{|c|}{$\begin{array}{c}\text { Main Result } \\
\text { deaths/patients }(\%)\end{array}$} & \multirow[t]{2}{*}{$\begin{array}{c}\text { Risk reduction }(\%) \\
(95 \% \text { IC) }\end{array}$} & \multirow[t]{2}{*}{$\mathrm{P}$} \\
\hline & & & Treatment & Control & & \\
\hline ISSI- $1^{5}$ & $\begin{array}{l}\text { Atenolol vs } \\
\text { control }\end{array}$ & $\begin{array}{c}\text { Vascular Mortality } \\
\text { in } 7 \text { days }\end{array}$ & $\begin{array}{c}313 / 8.037 \\
(3.9 \%)\end{array}$ & $\begin{array}{c}365 / 7.990 \\
(4.6 \%)\end{array}$ & $\begin{array}{c}15 \% \\
(1-27)\end{array}$ & $<0.05$ \\
\hline GISSI-1 ${ }^{6}$ & SK vs control & $\begin{array}{l}\text { Mortality } \\
\text { in } 21 \text { days }\end{array}$ & $\begin{array}{c}628 / 5.860 \\
(10.7 \%)\end{array}$ & $\begin{array}{c}758 / 5.952 \\
(13 \%)\end{array}$ & $\begin{array}{c}19 \% \\
(10-28)\end{array}$ & 0.0002 \\
\hline ISIS- $2^{7}$ & SK vs placebo & $\begin{array}{l}\text { Mortality } \\
\text { in } 35 \text { days }\end{array}$ & $\begin{array}{c}791 / 8.592 \\
(9.2 \%)\end{array}$ & $\begin{array}{c}1029 / 8.595 \\
(12 \%)\end{array}$ & $\begin{array}{c}25 \% \\
18-32\end{array}$ & $<0.0001$ \\
\hline ISIS- $2^{7}$ & $\begin{array}{l}\text { Aspirin vs } \\
\text { placebo }\end{array}$ & $\begin{array}{l}\text { Mortality } \\
\text { in } 35 \text { days }\end{array}$ & $\begin{array}{c}804 / 8.587 \\
(9.4 \%)\end{array}$ & $\begin{array}{c}1.016 / 8.600 \\
(11.8 \%)\end{array}$ & $\begin{array}{c}23 \\
(15-30)\end{array}$ & $<0.0001$ \\
\hline EMERAS $^{8}$ & $\begin{array}{l}\text { SK }>6 h \text { vs } \\
\text { placebo }\end{array}$ & $\begin{array}{l}\text { Hospital } \\
\text { Mortality }\end{array}$ & $\begin{array}{c}269 / 2.257 \\
(11.9 \%)\end{array}$ & $\begin{array}{c}282 / 2.277 \\
(12.4 \%)\end{array}$ & --- & NS \\
\hline $\begin{array}{l}\text { GISSI-2/ } \\
\text { International } \\
\text { Group of Study }{ }^{9}\end{array}$ & SK vs tPA & $\begin{array}{c}\text { Hospital } \\
\text { mortality } \\
(8,5 \%)\end{array}$ & $\begin{array}{c}\text { SK } \\
887 / 10.396 \\
(8.9 \%)\end{array}$ & $\begin{array}{c}\text { tPA } \\
\text { 929/10.372 } \\
---\end{array}$ & NS & \\
\hline ISIS-3 $3^{10}$ & $\begin{array}{l}\text { SK vs tPA } \\
\text { vs APSAC }\end{array}$ & $\begin{array}{l}\text { Hospital } \\
\text { mortality }\end{array}$ & $\begin{array}{c}\text { SK } \\
1.455 / 13.780 \\
(10.6 \%)\end{array}$ & $\begin{array}{c}\text { tPA } \\
1.418 / 13.746 \\
(10.3 \%) \\
\text { APSAC } \\
1.448 / 13.773 \\
(10.5 \%)\end{array}$ & --- & NS \\
\hline GUSTO-1 ${ }^{4}$ & $\begin{array}{c}\text { SK vs } \\
\text { accelerated tPA }\end{array}$ & $\begin{array}{l}\text { Mortality } \\
\text { in } 30 \text { days }\end{array}$ & $\begin{array}{c}\text { SK } \\
1473 / 20.173 \\
(7.3 \%)\end{array}$ & $\begin{array}{c}\text { tPA } \\
652 / 10.344 \\
(6.3 \%)\end{array}$ & $\begin{array}{c}14 \% \\
(6-21)\end{array}$ & $<0.01$ \\
\hline GISSI- $3^{11}$ & $\begin{array}{c}\text { Nitrate vs } \\
\text { control }\end{array}$ & $\begin{array}{l}\text { Mortality } \\
\text { in } 6 \text { weeks }\end{array}$ & $\begin{array}{c}617 / 9.453 \\
(6.5 \%)\end{array}$ & $\begin{array}{c}653 / 9.442 \\
(6.9 \%)\end{array}$ & -- & NS \\
\hline GISSI $-3^{11}$ & $\begin{array}{l}\text { Lisinopril vs } \\
\text { control }\end{array}$ & $\begin{array}{l}\text { Mortality } \\
\text { in } 6 \text { weeks }\end{array}$ & $\begin{array}{c}597 / 9.435 \\
(6.3 \%)\end{array}$ & $\begin{array}{c}673 / 9.460 \\
(7.1 \%)\end{array}$ & $\begin{array}{c}12 \% \\
(1-21)\end{array}$ & 0.03 \\
\hline ISIS-4 & $\begin{array}{c}\text { Nitrate vs } \\
\text { placebo }\end{array}$ & $\begin{array}{l}\text { Mortality } \\
\text { in } 35 \text { days }\end{array}$ & $\begin{array}{c}2.129 / 29.018 \\
(7.3 \%)\end{array}$ & $\begin{array}{c}2.190 / 29.032 \\
(7.5 \%)\end{array}$ & --- & NS \\
\hline ISIS-4 ${ }^{12}$ & $\begin{array}{c}\text { Captopril } \\
\text { vs placebo }\end{array}$ & $\begin{array}{l}\text { Mortality } \\
\text { in } 35 \text { days }\end{array}$ & $\begin{array}{c}2.088 / 29.028 \\
(7.2 \%)\end{array}$ & $\begin{array}{c}2.231 / 29.022 \\
(7.7 \%)\end{array}$ & $\begin{array}{c}7 \% \\
(1-13)\end{array}$ & 0.02 \\
\hline ISIS-4 ${ }^{12}$ & $\begin{array}{l}\text { Magnesium vs } \\
\text { control }\end{array}$ & $\begin{array}{l}\text { Mortality } \\
\text { in } 35 \text { days }\end{array}$ & $\begin{array}{c}2.216 / 29.011 \\
(7.6 \%)\end{array}$ & $\begin{array}{c}2.103 / 29.039 \\
(7.2 \%)\end{array}$ & --- & NS \\
\hline $\begin{array}{l}\text { ISIS = Internationa } \\
\text { Estreptoquinasa R } \\
=\text { tissue plasmino }\end{array}$ & $\begin{array}{l}\text { Studies of Infarct } \\
\text { publicas de Amer } \\
\text { en activator. }\end{array}$ & $\begin{array}{l}\text { GISSI = Gruppo Ital } \\
\text { ar; GUSTO = Globa }\end{array}$ & $\begin{array}{l}\text { Studio della Sop } \\
\text { of Streptokin }\end{array}$ & $\begin{array}{l}\text { nell'Infarto M } \\
\text { for Occludec }\end{array}$ & $\begin{array}{l}\text { lico; EMERAS = Est } \\
\text { hary arteries; SK = }\end{array}$ & $\begin{array}{l}\text { alticentrico } \\
\text { inase; } \mathrm{tPA}\end{array}$ \\
\hline
\end{tabular}

Epidemiological emergence of CVD in developing countries - At the beginning of the third millenium, it is evident that CVD has undoubtedly become a cause of morbidity, significantly contributing to increased mortality rates in most countries ${ }^{8,9}$. The increase and the recent decrease of epidemic CVD in developed countries has already been well documented. The identification of major risk factors through studies based on populations and strategies of effective control combined with community education and management directed at high-risk individuals has contributed to the decrease of mortality due to CVD, mainly in the industrialized countries. It is estimated that from 1965 to 1990, CVD mortality rates decreased approximately 50\% in Australia, Canada, France and the United States, and 60\% in Japan ${ }^{6}$. Countries in Western Europe had smaller reductions (20\%-25\%).

During recent years, a relatively rapid elevation in morbidity and mortality rates has been observed in developing countries, including Brazil. This elevation in developing countries is denominated by epidemiological transition and is explained by the demographic and healthrelated transition characterized by reduction in the mortality rates due to infectious diseases, increase in life expectancy and changes in life style resulting from urbanization. As more and more regions undergo the so-called epidemiological transition, deaths, especially premature death, occurring in the adult population will gradually become the greatest concern in public health. Research methods for reliable evaluation and monitoring of mortality in the adult population will probably anticipate this tendency (table IV) ${ }^{7}$. It is estimated that, during the pre- and posttransition period, these developing countries will double the problems related to morbidity and mortality rates due to CVD, involving social costs, costs attributed to clinical evaluation and management of CVD, as well as experiencing a decrease in productivity with an impact on individual, familial and social levels (table V).

In addition, it is estimated that 5.3 million deaths attributed to CVD occurred in developed countries in 1990, while in the developing countries, they were between 8 and 9 million, that is, a relative excess of $70 \%{ }^{8}$. Therefore, in 1990, the developing countries contributed with $68 \%$ of the total deaths due to noncommunicable diseases and with $63 \%$ of the world mortality due to CVD 9 . 


\begin{tabular}{|lccc|}
\hline \multicolumn{3}{|c|}{ Table IV - Mortality rates due to acute myocardial infarction } \\
(per 100,000) by region and sex (all ages)
\end{tabular}

ECME- European Countries with Market Economy; FSEC- Formerly Socialist European Countries; OAI- Others, Asia and Islands; SSASub-Saharan Africa; LAC- Latin American Countries; ME- Middle East.

\section{Impact of epidemiological studies at the national level} - The need to restrain epidemic CVD through reduction of CVD in terms of morbidity and mortality in developing countries is obvious and urgent. National strategies are necessary to reach this objective and they should be developed and effectively implemented. The essential components of any program for control of CVD should comprise the following items: 1) establishment of effective systems for estimation of CVD and its tendencies; 2) estimation of the levels of the conventional or established risk factors for CVD (i.e., tobacco use, hypercholesterolemia, hypertension, etc.) in representative samples of the population to identify the risk factors that require immediate intervention; 3 ) assessment of theemerging risk factors (i. e., glycemia, abdominal obesity, fibrinolytic state, homocysteine, etc) that can be of special relevance for the population in question; 4) identification of the determinants of the healthy behavior that influence the levels of conventional and emerging factors in the specific context of each society; 5) development of health policies that will integrate population-based measures to modify the risk of CVD and cost-effective strategies for individuals who have clinically manifest CVD or those with high risk of developing it ${ }^{10}$.
Information about the risk factors for CAD can be obtained through the following epidemiological strategies: a) prospective cohort studies, where the risk factors are assessed in a large number of individuals who are followed up until a sufficient number of clinical events are recorded; b) case-control studies where the risk factors are compared between the case (individuals with CAD) and control (individuals without CAD); and c) randomized clinical studies involving interventions where the specific risk factors are altered and the clinical outcomes in the intervention and control groups are compared. Each of these epidemiological strategies has its advantages and limitations. For example, the Framingham prospective cohort study required a follow-up of 10,000 individuals over 10 years before any reliable information could be drawn. The case-control study, when well-planned and performed with the reduction of biases and confounding factors in the planning, analysis and interpretation of the study data, constitutes an efficient strategy, providing information in a rapid and reliable manner about the importance of conventional and emerging risk factors for AMI. Epidemiological studies, mainly the prospective case-control type, will help more and more to identify the relation between risk factors and AMI in the Brazilian population. In the U. S. A., Canada and Europe, the association of conventional risk factors, such as tobacco use, hypertension, diabetes, cholesterol, etc., is well defined. Even though we extrapolate to the Brazilian population, the real and known impact of these factors has not yet been adequately determined in our population. The AFIRMAR (Avaliação dos Fatores de Risco para Infarto Agudo do Miocárdio no Brasil) study, now at the end of the recruiting phase, will definitely clarify the impact of the conventional risk factors for the development of the AMI in Brazil, allowing interregional comparisons. In addition, the relative impact of emerging risk factors for the development of AMI, such as lipoprotein a (Lpa), coagulation parameters, homocysteine, abdominal obesity, dietetic, psychosocial, genetic and socioeconomic factors, infection, and inflammation, will be internationally evaluated, including in Brazil, through the Inter-Heart study (A Global Case Control Study to Identify the Risk Factors

\begin{tabular}{|c|c|c|c|c|c|}
\hline \multicolumn{6}{|c|}{ Table V - Regional differences in the consequences of the cardiovascular disease (1990) ${ }^{9}$} \\
\hline Region & $\begin{array}{l}\text { Population } \\
\text { (millions) }\end{array}$ & $\begin{array}{l}\text { Mortality due to CVD } \\
\text { (thousands) }\end{array}$ & $\begin{array}{c}\text { Coronary Artery Mortality } \\
\text { (thousands) }\end{array}$ & $\begin{array}{c}\text { Vascular-cerebral Mortality } \\
\text { (thousands) }\end{array}$ & $\begin{array}{l}\text { "DALYs" Lost } \\
\text { (thousands) }\end{array}$ \\
\hline Developed regions & 1.144 .0 & 5.328 .0 & 2.678 .0 & 1.447 .9 & 39.118 \\
\hline Developing regions & 4.123 .4 & 9.016 .7 & 2.469 .0 & 3.181 .2 & 108.802 \\
\hline Established market economies & 797.8 & 3.174 .7 & 1.561 .6 & 782.0 & 22.058 \\
\hline Formerly socialist economies & 346.2 & 2.153 .3 & 1.116 .3 & 665.9 & 17.060 \\
\hline India & 849.5 & 2.385 .9 & 783.2 & 619.2 & 28.592 \\
\hline China & 1.133 .7 & 2.566 .2 & 441.8 & $1,271.1$ & 28.369 \\
\hline Others, Asia and Islands & 682.5 & 1.351 .6 & 589.2 & 350.4 & 17.267 \\
\hline Sub-Saharan Africa & 510.3 & 933.9 & 109.1 & 389.1 & 12.252 \\
\hline Middle East & 503.1 & 992.3 & 276.6 & 327.4 & 12.782 \\
\hline Latin America & 444.3 & 786.7 & 269.1 & 224.1 & 9.538 \\
\hline
\end{tabular}


for Acute Myocardial Infarction in Different Ethnic Populations). Through the AFIRMAR and Inter-Heart studies, all the conventional and emerging risk factors for the development of AMI will be assessed in the Brazilian population, allowing health policies to be planned and implemented, aiming at better cardiovascular health in our country through the extension of survival and reduction of disability related to CVD.

\section{Brazilian experience with epidemiological and randomized clinical studies. National Coope- ration - Brazilian Coordinating Center for Clinical Studies on Cardiology}

Ten years ago, Brazil began to participate in international randomized clinical studies through the EMERAS study (table VI), thus establishing the concept of scientific collaboration for high quality multicenter studies and valuable and reliable results. Through this national effort, approximately 84 hospitals in 16 states of our territory began collaborative work that has never ended during these 10 years. This effort culminated in the performance of epidemiological and randomized studies, generating international publications. (tables VI and VII).

This concept of multi-institutional and supra-society scientific cooperation has allowed Brazil to enter the international scientific investigative environment along with different universities and academic research organizations.

We believe that the continuity of this process will allow more and more national contributions in different areas of scientific investigation, thus providing a simultaneous and globalized growth of several cooperative institutions.

\section{Future directions}

Randomized controlled studies remain one of the most reliable methods for evaluating benefits and risks of promising treatments in large populations of patients. There is a continuous need for studies at reasonable costs. The careful preparation includes the knowledge of the pathophysiology of the disease, a good biological rationale for the treatment, an adequate understanding of the methodology used in clinical studies, and the careful conduction of pilot studies.

During the " 40 s and ' 50 s, large epidemiological studies were carried out, and during the '70s, ' 80 s, and ' 90 s, large randomized studies were carried out to reliably prove the hypotheses originated from those epidemiological studies and from small randomized studies. At the end of the ' 90 s and during the next decade, we will have to again conduct epidemiological studies to raise new hypotheses, to identify new risk factors and clinically significant questions that deserve to be assessed and integrated into clinical practice, justifying changes in the health policy at a national level.

The clinical randomized controlled study was probably the most important development in Medicine during this century. We can say that it is clearly established, having thus become an essential tool. We can also say that we are moving towards a Medicine where the clear and sound demonstration of benefits supporting clinical

\begin{tabular}{|c|c|c|c|c|}
\hline Study & Patients & Countries & Invest. Centers Brazil & Randomization Brasil \\
\hline $\begin{array}{l}\text { EMERAS }(89 \text { - 91) - Lancet 1993; 342: 767-72 } \\
\text { (Estudo Multicêntrico da Estreptoquinase nas Repúblicas da América do Sul) }\end{array}$ & 4.534 & 6 & 66 & 1.271 \\
\hline $\begin{array}{l}\text { RAPT ( } 90 \text { - 92) - Circulation 1994; 89: 588-95 } \\
\text { (Ridogrel Aspirin Patency Trial) }\end{array}$ & 907 & 3 & 10 & 224 \\
\hline $\begin{array}{l}\text { ISIS-4 }(91-93) \text { - Lancet } 1995 ; 345: 669-85 \\
\left.\text { (International Study of Infarct Survival }-4^{\text {th }}\right)\end{array}$ & 58.050 & 32 & 84 & 3.371 \\
\hline $\begin{array}{l}\text { CORE }(94 \text { - 95) - Circulation 1997; 96: 192-201 } \\
\text { (Collaborative Organization for RheothRx Evaluation) }\end{array}$ & 2.954 & 16 & 19 & 374 \\
\hline $\begin{array}{l}\text { COBALT ( } 95 \text { - 96) - N Engl J Med 1997; 337: 1124-30 } \\
\text { (Continuous Infusion Versus Double Bolus Administration of Alteplase) }\end{array}$ & 6.940 & 23 & 18 & 225 \\
\hline $\begin{array}{l}\text { PARAGON A }(95-96) \text { - Circulation 1998; } 97: 2386-95 \\
\text { (Platelet IIb/IIIa Antagonist for the Reduction of Acute Coronary } \\
\text { Syndrome Events in a Global Organization Network) }\end{array}$ & 2.282 & 19 & 1 & 1 \\
\hline $\begin{array}{l}\text { GIK Pilot Study (94 - 96) - Circulation 1998; } 98: 2227-2234 \\
\text { (Glucose-Insulin-Potassium in Acute Myocardial Infarction) }\end{array}$ & 500 & 3 & 8 & 61 \\
\hline $\begin{array}{l}\text { OASIS Registry (96 - 97) - Lancet 1998; 352: } 507-14 \\
\text { (Organization to Assess Strategies for Ischemic Syndromes) }\end{array}$ & 7.911 & 6 & 20 & 1.477 \\
\hline $\begin{array}{l}\text { OASIS-2 }(97-98) \text { - Lancet } 1999 ; 353: 429-38 \\
\text { (Organization to Assess Strategies for Ischemic Syndromes) }\end{array}$ & 10.141 & 14 & 21 & 596 \\
\hline $\begin{array}{l}\text { RESOLVD Pilot Study (96 - 97) } \\
\text { (Randomized Evaluation of Strategies for Left Ventricular Dysfunction) }\end{array}$ & 769 & 5 & 5 & 83 \\
\hline $\begin{array}{l}\text { ASSENT-2 }(97-98) \\
\text { (Assessment of the Safety and Efficacy of a New Thrombolytic) }\end{array}$ & 17.500 & 23 & 16 & 280 \\
\hline $\begin{array}{l}\text { SYMPHONY }(97-99) \\
\text { (Sibrafiban Versus Aspirin to Yield Maximum Protection from Ischemic } \\
\text { Heart Events Post Acute Coronary Syndromes) }\end{array}$ & 9.245 & 20 & 9 & 120 \\
\hline
\end{tabular}




\begin{tabular}{|c|c|c|c|c|}
\hline Study & Patients & Countries & Invest. Centers Brazil & Randomization Brazi \\
\hline \multicolumn{5}{|l|}{ HOPE (95 - 99) } \\
\hline (Heart Outcomes Prevention Evaluation) & 9.541 & 18 & 19 & 466 \\
\hline AFIRMAR (97 - 98) & & & & \\
\hline (Avaliação dos Fatores de Risco para Infarto Agudo do Miocardio no Brasil) & 4.000 & 1 & 125 & \\
\hline $\begin{array}{l}\text { OASIS-3 - PEGASUS (98 - 99) } \\
\text { (Peg Hirudin Study in Unstable Ischemic Syndromes) }\end{array}$ & 8.000 & 20 & 26 & \\
\hline OASIS-4 - CURE $(98-99)$ & & & & \\
\hline (Clopidogrel in Unstable Angina to Prevent Recurrent Ischemic Events) & 7.000 & 20 & 17 & \\
\hline $\begin{array}{l}\text { PARAGON B }(98-99) \\
\text { (The PARAGON B Trial) }\end{array}$ & 4.000 & 20 & 8 & \\
\hline $\begin{array}{l}\text { SYMPHONY-2 }(99-2000) \\
\text { (The } 2^{\text {nd }} \text { SYMPHONY Trial) }\end{array}$ & 8.400 & 20 & 07 & \\
\hline $\begin{array}{l}\text { GIK-2 (98-2000) } \\
\text { (Glucose-Insulin-Potassium in Acute Myocardial Infarction) }\end{array}$ & 6.000 & 7 & 50 & \\
\hline $\begin{array}{l}\text { Inter-Heart (99-2000) } \\
\text { (A Global Case Control Study to Identify the Risk Factors for AMI in } \\
\text { Different Ethnic Populations) }\end{array}$ & 20.000 & 22 & 30 & \\
\hline
\end{tabular}

decision-making has been replacing the isolated medical opinion that is not related to available scientific evidence.

More important than the identification of new treatments is the correct incorporation of the already existing effective treatments. These treatments have to be effective in the real world conditions of the daily clinical practice and not only in the ideal scenario of the randomized controlled study.
In the new millenium, four new pathways are being opened in regard to scientific investigation applied to clinical cardiological practice: 1 ) epidemiological studies; 2 ) studies aiming to incorporate effective therapies into clinical practice; 3 ) cost-effectiveness and cost-utility studies; and 4) evidence-based cardiology as a paradigm for clinical decision-making in cardiology.

\section{Referências}

1. Yusuf S, Collins R, Peto R. Why do we need some large, simple, randomized trials? Stat Med 1984; 3: 409-20.

2. Peto R. Clinical trial methodology. Biomedicine 1978; 28: 24-36.

3. Peto R, Collins R, Gray R. Large-scale randomized evidence: large, simple trials and overviews of trials. In: Warren KS, MostellerF, eds-Doing more Good than Harm: The Evaluation of Interventions. Proceedings of the New York Acad Sci, 1993: 703.

4. The GUSTO Investigators. An international randomized trial comparing four thrombolytic strategies for acute myocardial infarction. N Engl J Med 1993; 329: 673-82.

5. Flather MD, Farkouh ME, Yusuf S. Large simple trials in cardiovascular disease: their impact on medical practice. In: Califf R. Cardiovasc Dis, 1996: 131-44.
6. Murray CJL, Lopez AD. Global mortality, disability, and the contribution of risk factors: Global Burden of Disease Study. Lancet 1997; 349: 1436-42.

7. Murray CJL, Lopez AD. Mortality by cause for eight regions of the world: Global Burden of Disease Study. Lancet 1997; 349: 1269-76.

8. Lopes AD. Assessing the burden of mortality from cardiovascular disease. World Health Stat Q. 1993; 46: 91-6.

9. Murray CJL, Lopez AD. Global Comparative Assessment in the Health Sector. Geneva, Switzerland: World Health Organization, 1994

10. Reddy KS, Yusuf S. Emerging epidemic of cardiovascular disease in developing countries. Circulation 1998; 97: 596-601. 